transmissability through the female ${ }^{9}$. Such a fragment is under strong selective pressure to change the sex of the female zygotes it normally finds itself in to more congenial male zygotes.

\section{Method of spread}

Once psr has evolved, it may spread. Werren points out ${ }^{10}$ that if $p s r$ is transmitted by all the sperm of an infected male in a spatially unstructured population, the equilibrium frequency of $p s r$ is $(2 x-1) / x$, where $x$ is the proportion of eggs that female wasps fertilize. This means that $p s r$ will not persist unless $x>0.5$, that is, unless female wasps fertilize more than half their eggs, which would mean producing a female-biased sex ratio in an uninfected population. $N$. vitripennis does indeed do this because its populations are spatially structured with mating occurring among the offspring of small groups of females, with consequent very high levels of local mate competition ${ }^{11.12}$. Although this female-biased sex ratio favours the spread of $p s r$, another feature of spatially structured populations tends to hinder its spread: if all the females laying their eggs in a single patch (perhaps a localized population of housefly larvae) have mated with psr males, all their progeny will be sons who will die without mating. Theoretical models of the spread of $p s r$ in spatially structured populations indicate that persistence is possible only for intermediate levels of population subdivision $^{13}$.

Ironically, the persistence of $p s r$ may be markedly enhanced by the presence of maternally inherited cytoplasmic factors that cause female-biased sex ratios ${ }^{13}$, two of which are known from $N$. vitripennis ${ }^{6.14}$. No systematic search for extrachromosomal sex-ratio factors has been undertaken in Hymenoptera other than in $N$. vitripennis. Of all groups with variable sex ratios, parasitic wasps were thought to be the best understood: perhaps there is a whole new level of complexity yet to be explored.

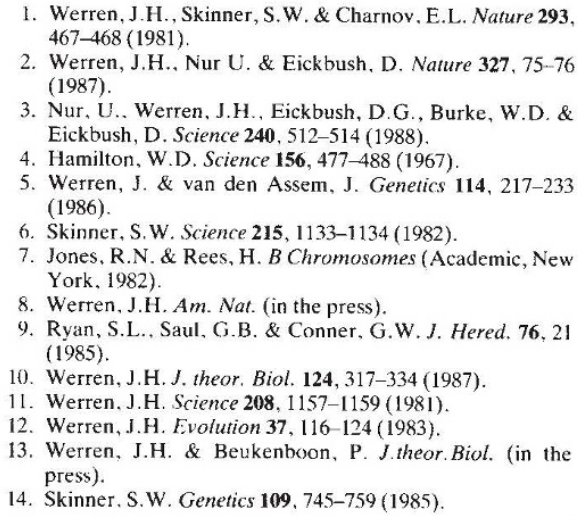

H. C. J. Godfray is in the Department of Pure and Applied Biology, Imperial College, Silwood Park, Ascot, Berkshire SL5 7PY; Paul $H$. Harvey is in the Department of Zoology, University of Oxford, Oxford OXI 3PS, UK.

\section{Raymond Arthur Dart (1893-1988)}

Raymond Dart died in Sandton, Johannesburg, on 22 November 1988, almost 64 years to the day since he had received the chunk of sandy limestone containing the Taung skull that was to create his reputation. Dart recognized certain extraordinary features of the skull - its relatively erect poise, small canine teeth and endocranial capacity, scarcely differing from those of extant apes. But he noted also that the form of the brain was human-like in its parietal lobe. In particular, he recognized the impression of what he took to be the lunate sulcus. It was well back, as in modern man, and not well forward as in modern apes. He then made a great intellectual leap: he

\section{IMAGE UNAVAILABLE FOR COPYRIGHT REASONS}

\section{Dart-effected a revolution in knowledge.}

interpreted this curious blend of traits as evidence for the former presence in Africa of an anthropoid that had moved substantially in a human direction. This he claimed in his historic paper in Nature on 7 February 1925 . He named the species Australopithecus africanus.

Many deterrents to the acceptance of Dart's claim were predicated on the accepted wisdom of the day: the idea that Asia, not Africa, had cradled mankind; and the notion that the brain had expanded early in hominization, a view supported by the features of the ill-famed Piltdown bones. Moreover, the Taung specimen was of a child and, it was averred, the nature of the adult could not have been predicted. Arthur Keith, with most later investigators, rejected the evidence of the lunate sulcus, holding that its position could not be identified with certainty on the Taung endocast.

The main controversy Dart stirred up did not abate for 25 years, when many new specimens from the Transvaal were compared with the skeletons of modern apes. It was realized that, even if one discounts the lunate sulcus, enough other features mark the specimen not only as unique, but as morphologically intermediate in several respects between apes and men. Only then did it emerge that Dart's claim had been basically correct and, indeed, that there was every justification for classifying the fossils as members of the Hominidae.

Dart's recognition and interpretation of the significance of Australopithecus remains one of the great steps forward in the history of palaeoanthropology. With hindsight, the essence of his 1925 contribution lay in his willingness to overlook the small brain size of Australopithecus, in the face of other strong pointers to its evolutionary status. Brain-size alone, he declared in a 1956 paper, was not the acid test; the form of the brain was more important. Late in life, Keith, the first of Dart's main opponents, generously acknowledged that he had been wrong and Dart right: he proposed to call the australopithecines 'Dartians'.

After World War II, following discoveries of fossil baboons at Makapansgat, northern Transvaal, Dart was lured back into the field - and a new chapter opened. Intrigued by the thousands of fossilized, broken antelope bones in that cave deposit, he proposed in 1955 that the bones had been broken deliberately, fashioned and used by the australopithecines. His proposed Osteodontokeratic culture was based on the use as implements of bones, teeth and horncores, especially of ungulates. This notion has now been largely rejected, as evidence has built up that big cats, hyenas and porcupines were probably the bone breakers and accumulators.

But Dart's hypothesis had a remarkable spin-off. When he first proposed his bonetool theory in 1955 , scarcely anything was known of how animals, or agents like sunlight and water, affected bones after death. To disprove Dart's proposal, a host of new studies were made of the effects of such biotic and physical agencies on bones. A new scientific discipline came into being, called taphonomy. Dart's ideas were a major catalyst in the birth of this new field. Thus, it can be claimed of Dart that he effected a revolution in knowledge about man's place in nature, and that indirectly he triggered the foundation of a new scientific discipline.

Raymond Dart was born during the flood that swept Queensland, Australia, in 1893. He read science at the new University of Queensland, Brisbane, and medicine at Sydney. After serving in the Australian Army Medical Corps, he worked under Elliot Smith in the Anatomy Department at University College, London. There followed six months as a Rockefeller fellow in the United States. In 1923, be became head of the Department of Anatomy at the newly formed University of the Witwatersrand Medical School, a position he held for 36 years. Dart was a prime architect of the Medical School and a maker of men. The Raymond Dart Collection of Human Skeletons is one of the tangible monuments to his initiative and foresight. Phillip V. Tobias

Phillip V. Tobias is Professor of Anatomy and Human Biology at the University of Witwatersrand Medical School, Parktown 2193, South Africa. 